\title{
SPONTANEOUS DISLOCATION OF THE CERVICAL SPINE IN CHILDHOOD
}

BY

\author{
R. M. I. MACKAY \\ From the Royal Hospital for Sick Children, Edinburgh
}

This paper is based on a series of 10 cases of spontaneous dislocation of the cervical spine. In the 10-year period, 1946 to 1955 , nine cases were seen out of a total of 19,270 surgical admissions. A further case was seen in 1956.

I.H., a boy aged $3 \frac{1}{2}$ years, was admitted with the history that 10 days previously he had been playing with his uncle who had been tossing him into the air and catching him again. One hour later the child complained of pain in his neck and of earache. His mother noticed that he was holding his neck rigidly and so put him to bed. The next day the family doctor saw him and found that he had enlarged, tender lymph nodes on both sides of the neck and ordered hot fomentations. The lymph nodes subsided but the pain and stiffness of the neck persisted so he was referred to hospital. He was pale and was walking about with his head poking forwards, the cervical muscles were tense and there was a depression just below the occiput. Radiographs showed that the second cervical vertebra had slipped forwards on the third and that there was a soft tissue swelling behind the pharynx. He was treated by hyperextension, with a flat pillow under the shoulders, and a head halter with a $1 \mathrm{lb}$. weight. Next day the radiograph showed some improvement. Ten days later he developed dyspnoea and dysphagia and the radiograph showed that the retropharyngeal abscess had increased in size. Four days later the dyspnoea became urgent and the abscess was palpable in the neck behind the larynx and trachea. It was aspirated by a lateral approach behind the left sternomastoid muscle and $70 \mathrm{ml}$. of thin pus was obtained. Streptococcus haemolyticus was grown. Two days later further aspiration yielded $148 \mathrm{ml}$. of pus, and this time 100,000 units of penicillin were injected into the cavity. Intramuscular penicillin was also given. A final aspiration three days later yielded $40 \mathrm{ml}$. and the abscess subsided. Traction in hyperextension was maintained for two months and then he wore a brace for six months. He was last seen, aged $15 \frac{1}{2}$ years, and was very well.

S.W., a boy aged $5 \frac{1}{2}$ years, jumped off a $\log$ nine days earlier and felt pain in the neck. He walked into hospital with his chin cupped in his hand. His mother stated that he kept his chin supported all the time, even when he was

* A paper read at the meeting of the British Association of Paediatric Surgeons held in Edinburgh in June, 1957.

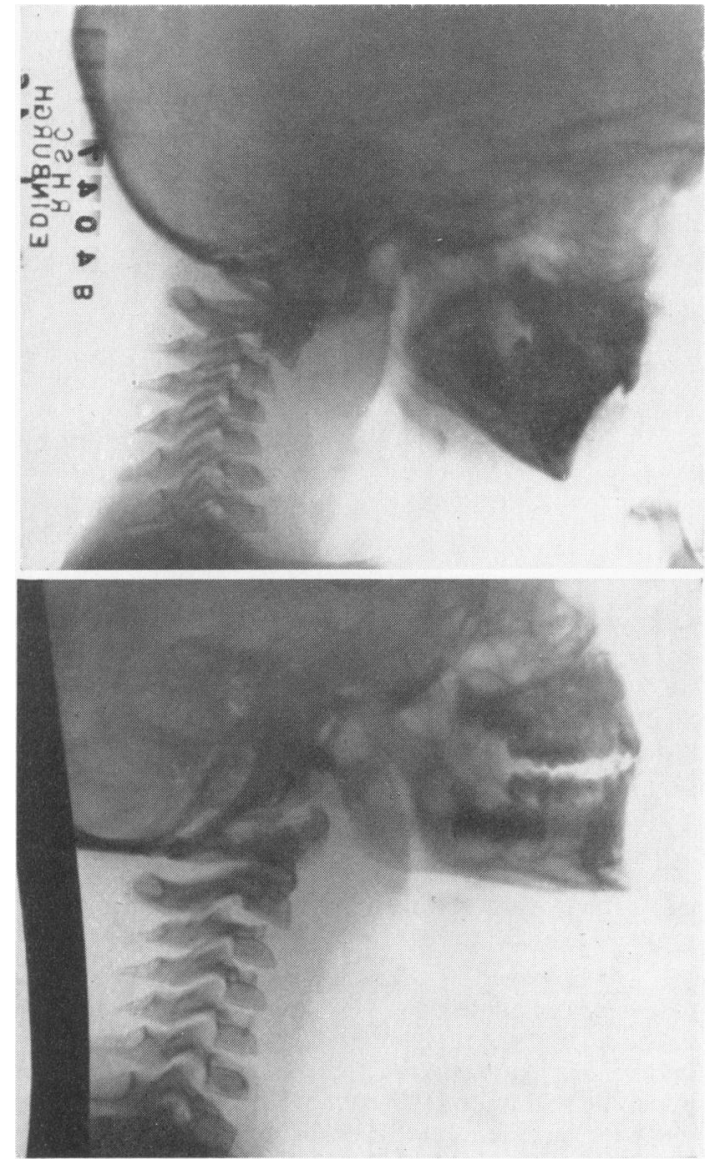

FIG. 1.-Radiograph (above) of Case I.H. on admission, showing retropharyngeal abscess with subluxation.

Radiograph, showing reduction, with the abscess before aspiration.

eating. His head was poking forwards, the cervical muscles in spasm and he had enlarged tender glands on both sides of the neck. Radiographs showed subluxation of the second cervical vertebra on the third. $\mathrm{He}$ was treated by extension with a head halter and $1 \mathrm{lb}$. 


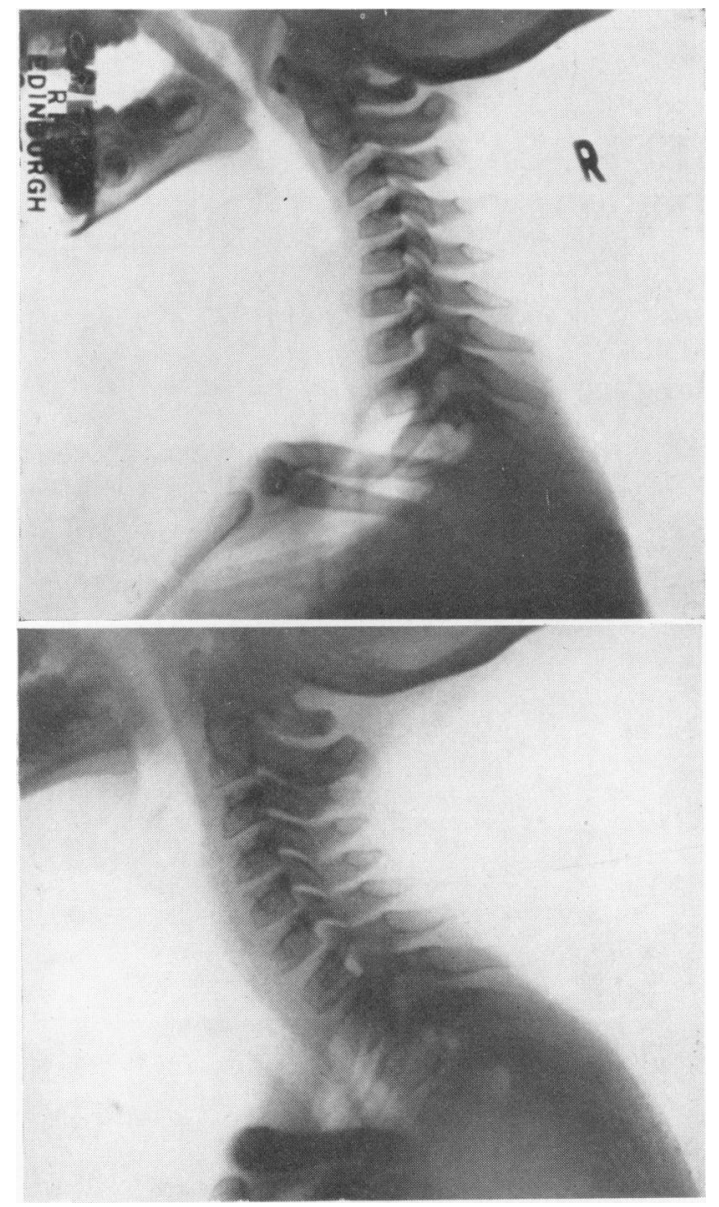

FIG. 2.-Radiograph (above) of Case S.W. showing subluxation of C. 2 on C. 3 on admission nine days after the injury. Radiograph (below), showing reduction.

weight for 11 days and then he wore a plaster collar for a month.

B.T., a boy aged $8 \frac{1}{2}$ years, tripped and fell on his head 10 days before admission. He complained of pain in the left shoulder at the time but not subsequently. Five days later he fell again on the right shoulder but when examined he had full movements of the cervical spine. Five days later he was admitted to hospital with pain in the neck; his head was tilted forwards and to the left. The cervical nodes were not enlarged but he had pharyngitis. Radiographs showed subluxation of the second on the third cervical vertebra. He was treated by head traction for one month, a plaster jacket for two months and a brace for three months.

H.G., a girl aged $1 \frac{1}{2}$ years, tumbled backwards on to her head three days before admission. She got up from the floor and appeared to be all right. The next day her mother noticed that she was holding her neck rigidly with the chin jutting forwards. On admission, she had enlarged cervical lymph nodes, and a spasm of the cervical muscles. Radiographs showed subluxation of the second on the third cervical vertebra and also of the third on the fourth. She was treated with head traction for five days, by which time the glands had subsided and the muscle spasm disappeared. She was then allowed to move about in bed as she wished and after 10 days was allowed home. She had no further trouble.

P.H., a boy aged 9, was seized by a severe pain in his neck while dressing. He came up to hospital the same day. His head was tilted forwards and to the left, and the cervical lymph nodes were enlarged. Radiographs showed subluxation of the atlas. The deformity was reduced by head traction.

F.H., a boy aged 3 years, had suffered from coryza for six weeks. The day before admission, while sitting quietly, he suddenly put his hand to the back of his neck and complained of pain. His head was held forwards and downwards. There were enlarged nodes in the left side of the neck. Radiographs showed that the third cervical vertebra was dislocated forwards on the fourth. Reduction was obtained by hyperextending the neck over a pillow and sandbags at the sides of the head. Five days later he was moving about freely in his bed. Supervision was continued for a further five days and, when seen one montn later, he was well with full movement of the neck.

R.H., a girl aged $5 \frac{1}{2}$ years, had had tonsillitis and a stiff neck for three weeks. She also had enlarged cervical lymph nodes and radiographs showed dislocation of the second on the third cervical vertebra. She was treated by head traction and afterwards wore a plaster fillet jacket for two months and a brace for a further two months.

M.G., a girl aged 10 years, had attended hospital six months previously with tuberculous cervical lymphadenitis with abscess formation. The abscess had been healed for four months. Two days earlier she had wakened with a stiff neck. She was pale and in pain. She had a severe right-sided torticollis, but no further enlargement of the cervical nodes. Radiographs showed that the second cervical vertebra was dislocated forwards on the third. The dislocation was reduced by head traction and she then wore a plaster fillet jacket for four months followed by a brace for two months. She remained well thereafter.

L.H., a girl aged 10 years, had had her adenoids removed two weeks previously. Two days later she developed a painful stiff neck with a right-sided torticollis. The cervical lymph nodes were enlarged and tender. Radiographs showed that the second cervical vertebra was displaced forwards on the third, and the third on the fourth. She was treated by head traction over a pillow for eight days and then wore a plaster collar for one month.

J.H., a girl aged 6 years, had had her tonsils and adenoids removed 18 days earlier. Four days later she developed a stiff neck. Her head was tilted to the right 


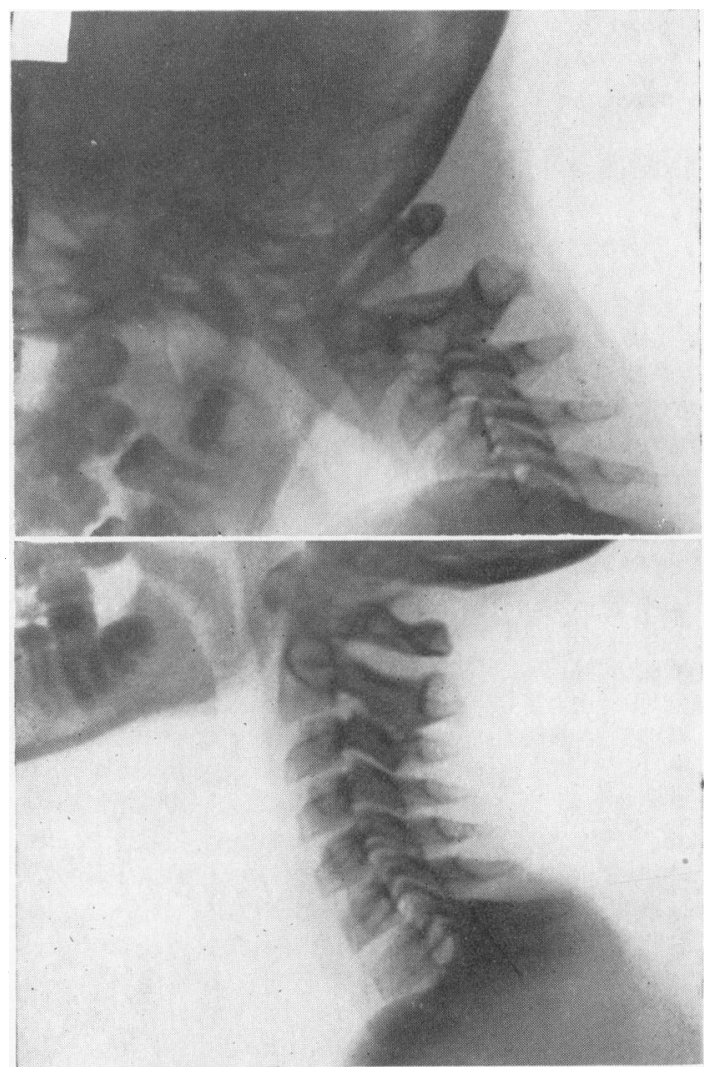

FIG. 3.-M.G. wakened in the morning with a stiff neck. Radiograph (above) shows condition on admission to hospital two days later. Radiograph (below), showing reduction.

and the cervical nodes were enlarged. Radiographs showed dislocation of the second on the third cervical vertebra. The dislocation was reduced by hyperextension over a pillow and eight days later a plaster collar was applied and she wore this for a month.

\section{Discussion}

Watson-Jones and Roberts (1934) reported a series of 21 cases of subluxation of the cervical spine in children, but in all their cases the atlas was affected. All the cases were associated with infection, such as tonsillitis, upper respiratory infection, acute mastoiditis or cervical adenitis. One child developed paraplegia but recovered completely.

Sulamaa (1949) reviewed the literature and pub- lished two further cases in which the subluxation involved the second cervical vertebra.

In the present series of 10 cases, nine had cervical adenitis and the tenth pharyngitis. The dislocation was multiple in two cases; in only one case was the atlas involved and in the others the second or third cervical vertebra. The spinal cord was not affected and all the children walked into hospital. The length of the history varied from one day to three weeks. No disease was ever demonstrated in the vertebral bodies although all cases were followed up for several months and some even for years, and in no case did the lesion recur. A lateral radiograph taken with the neck in the position in which the child is holding it will usually demonstrate the lesion, but in mild cases the neck has to be flexed or the lesion will be missed.

The cause of the dislocation is hyperaemia of the retropharyngeal tissues, the retropharyngeal lymph nodes and the vertebral ligaments. These ligaments are weakened by the hyperaemia so that minimal trauma or even normal movements are sufficient to produce the dislocation. Thereafter spasm of the cervical muscles prevents further deformity. Reduction can always be obtained by slight hyperextension of the neck obtained by placing a low pillow under the shoulders and it is maintained by light traction with a $1 \mathrm{lb}$. weight and a head halter, or by placing the head between sandbags with a towel wrapped round them stretched over the forehead. When once the pain, spasm and cervical adenitis had subsided the children were allowed to move about in bed at will in the mild cases. When the infection had been more severe, or the history long, plaster-either as a collar or as a fillet jacketwas used.

\section{Summary}

Ten cases of spontaneous dislocation of the cervical spine in childhood are recorded.

All cases were associated with cervical adenitis or infection of the nasopharynx.

The history varied from one day to three weeks and all patients walked into hospital.

No neurological lesions were demonstrated.

All were reduced by simple hyperextension, some with and some without extension.

The results were uniformly satisfactory.

\section{REFERENCES}

Sulamaa, M. (1949). Acta chir. scand. 98, 212.

Watson-Jones, R. and Roberts, R. E. (1934). Brit. J. Surg., 21, 461. 